\title{
New Functionality, Security and Protection of CCTV Systems: Technological Progress and Digital Society Development
}

\author{
$R$. Vaníčková ${ }^{1, *}$ \\ Corresponding author: vanickovaradka@gmail.com. \\ ${ }^{1}$ Institute of Technology and Business in České Budějovice, České Budějovice, Czech Republic
}

\begin{abstract}
The objective of the paper is to analyse and evaluate the current state of the project of integrated security CCTV systems including the description of the original plan, the course of multiannual implementation, analysis of partial results. Next discussion of the current state and developmental technological changes in information and communication systems of the 21 st century digital society including accepting the trends in developments, changes and forecasts in the field of cyber security. In the analytical part of the contribution, the author analyses and evaluates the planned/unplanned activities, the course of multiannual implementation and achievement of the strategic objectives including the characteristics of the current protection and security of the CCTV systems and the impacts of the installed security and monitoring systems in a banking institution. The final part of the contribution evaluates the project success with respect to the protection and security of the systems.
\end{abstract}

Keywords: digital society, technological progress, cyber security, project of integrated security, protection of CCTV systems.

\section{Introduction}

The beginning of the project is connected with the creation of the bank strategy influenced by a new owner entering the banking sector. The concept of the bank management is a more professional approach to the management of the institution, improvement of the products and services portfolio including setting up services parameterization, consolidation of the processes, creation of the control and security mechanisms, effective use of available sources and information. The management of the banking institution decided to map, change, and innovate the situation unclear in terms of processes, organization, and economics, related to the security and protection of the camera and monitoring systems in order to be in line with the current trends in IT. For the purposes of market research and monitoring the stateof-the-art, the methodology of elaborating the feasibility study within the implementation of the integrated security project into the banking sector. A parametrically selected supplier was approached, who acted as an integrator of security services under a framework contract on complex services provision [1]. The subject of the services offered was the modification of the rights and obligations of the contractor and the customer by the security specialists and external suppliers, hereinafter referred to as "complex security services", which includes activities such as physical surveillance of property and persons, monitoring of alarm and technical signals [2, 3], including intervention [9], district car patrols and mobile patrols [5], supply and installation of security systems [6], service for security systems operation [7], technical services for protecting property and persons [8]. Complex activities do not include the activities provided by the customer through the IT department, department of financial analysis of the department of extraordinary investigation. The rights and obligations of the contracting parties, i.e. the contractor and the customer in accordance with the framework contract concluded, are governed by the relevant provisions specified in the contract, including the annexes. The objective of the complex security services in the given extent and partially quoted in the relevant Act and the implementing regulations is to strive for eliminating undesired phenomena, risks, and adverse events that could affect the security and protection of property and persons $[9,10]$, employee performance, goodwill and the image of the banking institution across the range of the organizational structure. The protection of health and human life of the permanent employees and the clients/customers, external workers, and suppliers is subsidized in integration with the externalities in the customer's premises and control activities by compliance with legal regulations and regime measures $[11,12]$. The customer's competence includes the protection and surveillance of the property including the prevention of undesirable influences against the customer's interests and his/her rights related to the protection of the operation in the customer's workplace [13]. Preventive protection and avoiding the occurrence and consequences of extraordinary events in the customer's premises is an inseparable part of the contractual arrangements [14]. In the preparation phase of the project, a large number of partial adjustments and specific activities focused on the local and regional market research in the Czech Republic were performed, as well as mapping the technological possibilities and alternatives of negotiations with the producers and suppliers of modern technologies of securing CCTV systems with the emphasis on the feasibility study and situational analysis of protecting the security and monitoring systems security [15]. The project was started in parallel at more levels at the same time and it had an impact on the suppliers and customers departments, e.g. technical department, human resources, economic and financial departments in cooperation with the partner 
subjects involved [16]. The project team consisted of a project manager supervised by a CFO and directly supervised by the CEO of the banking institution.

\section{Materials and Methods}

The objective of the paper is to analyse and assess the state of the project of the integrated CCTV systems. For preparation of a feasibility study, the analysis of written documents from primary and secondary sources, and internal documents of the project contracting partners were used, as well as relevant technical literature and sources, literary research, and formulation of theoretical knowledge of CCTV systems. The first activity was a description and analysis of the current state, plan, and the course of the project implementation based on the analysis of the banking institution micro-environment, the analysis of technologies and security services, analysis of specific banking processes and security standards suppliers, the analysis of the main characteristics of the situation. In order to get responses to the survey conducted in April and June 2018 for economically productive men and women of complete secondary and university education in economics (a total of 25 employees of a branch of a bank in the CR, South Bohemia, České Budějovice district), the following research questions were formulated:

What were the outcomes and impacts of the integrated security project?

What was the result of installing CCTV systems in and outside the bank institution?

Can a well-installed security and monitoring device protect or prevent a hacker attack?

Summarized background material for the introduction part of the contribution on the given topic, interpretation and empirical generalization of knowledge and findings in the final part of the contribution.

\section{Results}

\subsection{Project Activity Baseline Characteristics}

The start of the project activities was preceded by monitoring and mapping the current situation in bank security systems, and study of security service offers, technological and technical options, including internal survey of the baseline in security and protection of the bank with support alternation of synergy effects. The baseline of security and protection of property and persons was not clear and well arranged with low transparency of the organisational, economic, financial and process structure of systems. The initial findings offered new knowledge of the technologies from at least two dozens of foreign producers. ATMs were connected to the Police of the Czech Republic who gradually desisted the monitoring of private properties. Bank branches were mostly autonomous as regards the management and decision making on the functionality of CCTV systems because the authorised managers and experts contacted businesses providing repair and maintenance services in the local and regional market with different market prices, parametric availability and quality. The organisational structure for cost allocation and controlling of financial and non-financial operations was not defined and not approved at the corporate level by the director of the bank institution in Prague, Czech Republic, but by an authorised team of regional officers. The decision-making autonomy of bank branches and representatives of the property management was not transparent as regards the selection of technology vendors and the associated security of monitoring systems, e.g. security doors and windows. The management of a bank branch made decisions and negotiated with a limited number and scope of rights and powers and with a lacking visible concept because standard procedures, defined price levels, and partial solutions for the selection of suitable contractors, and other necessary business parameters did not exist. Written documents did not have a standardized format, e.g. security guidelines, rules of operation, risk and security studies and other supporting tools. Industrial safety and fire protection was decentralised with no archives and data backups. Insourcing of security specialists, e.g. reducing the number of staff and consequent transfer to the contractor for the sake of integration of security services and autonomy of branches when selecting physical and extraordinary security staff or patrols, was another adverse finding of lacking integrity of security services. For the purpose of entering into and execution of a general agreement with the service integrator, an action plan was developed to map the baseline consisting in priorities of centralized surveillance by security forces of CCTV objects, technological standardisation and integration unification, providing selected buildings with technological backgrounds, building categorisation and passports, cost planning, control and allocation, reduction of the number of contractors and subcontractors, and establishing rules and standards for the protection and security of property and persons. The feared threats included internal risk, most often fluctuation and a high sickness rate of employees as well as external risk of contractors resulting in security incidents of non-updated or informal written documents with high risk of penalties or sanctions caused by ATM disconnection. No less feared risk was corruption in awarding capital projects causing deliveries without consistent control and standardisation of work processes, a plenty of technological contractors specialised in repairs, maintenance, services preferring private interest to public interest, wasting money resulting in uncontrolled efficiency, effectiveness and functionality of spent resources. Decentralised data and information on the price level intended for installation and repairs of technologies and managing possible incidents, e.g. non-standard setting of escalation procedures, was identified as the baseline threats to start activities of the planned project. The bank branch management, the department 
for protection of property and security of persons urged to change the current situation and implement a new functional security system supported by standardised written documents of partial processes and the implementation of uniform technology aimed at cost savings, in particular payroll, and improvement of work performance of permanent employees.

\subsection{Project Implementation Process}

It is useful to point out that the comprehensive, articulated and secondary implementation of project goals and objectives took a very long time, more than ten years. Large process changes and time consuming approval procedures were completed over this period of time. The creation of profiles and specialisation of security services was associated with planning of technical implementation and required significant financial subsidies and time distributed within several years. The actual implementation of investment plans and the unification of the related content and formal documents were preceded by challenging agreements between several business partners. The resulting solutions and the format of project plans and project documentation were often changed and modified to reflect innovations in legislation and validation of partial laws and regulations. The initial definition of requirements and service distribution in respect of the client needs, including controlling activities consisted in development of 30 new service reports with pre-defined accounts, cost centres, contact addresses and a set of services. Furthermore, external assistance was available for development of a new billing and information system since it was not manageable to cover 12,000 - 14,000 invoice items during one calendar month. The optimisation of the branch network managed by the business strategy of the bank consisted in reduction and reallocation of branches, upgrading the information and communication technologies with the assistance of the property management department and marketing department and co-operation with public and local authorities. The necessary involvement of designers, design bureaus and technical supervision transformed the summary requirements of the contracting authorities for user practice because sophisticated equipment of computer networks, furniture, including HVAC systems, were required from contractors. Due to the large scope of activities pursued and the number of tasks assigned, the directors and representatives of the controlling departments of the client and the contractor as well as independent consultants and advisors had to discuss and strategically document and evaluate the project outcomes. The yearly balance of services and activities provided in a written document signed by the authorised representatives of the involved parties was a necessary project activity of the authorised members of the project team.

\subsection{Evaluation of Project Outcomes}

The centralisation of CCTV systems and their unification can be considered as a completed task. The client has gradually changed to so-called on-line remote transmission which allows to carry out the general technical operations, e.g. functionality monitoring, process restart, system setup changes and other activities. Remote technology management has fostered more comfortable control, faster transmission, and the provision of data and events from systems. Technologies are installed to support the technological progress and development and CCTV systems. The stepwise replacement of black and white cameras for colour cameras, later IP (digital) cameras with higher resolution, shooting and zoom options was a major progress. Figure 1 gives a practical example of photos from older installations of security and monitoring systems with lower resolution, black and white images and less identifiable contrejour environment.
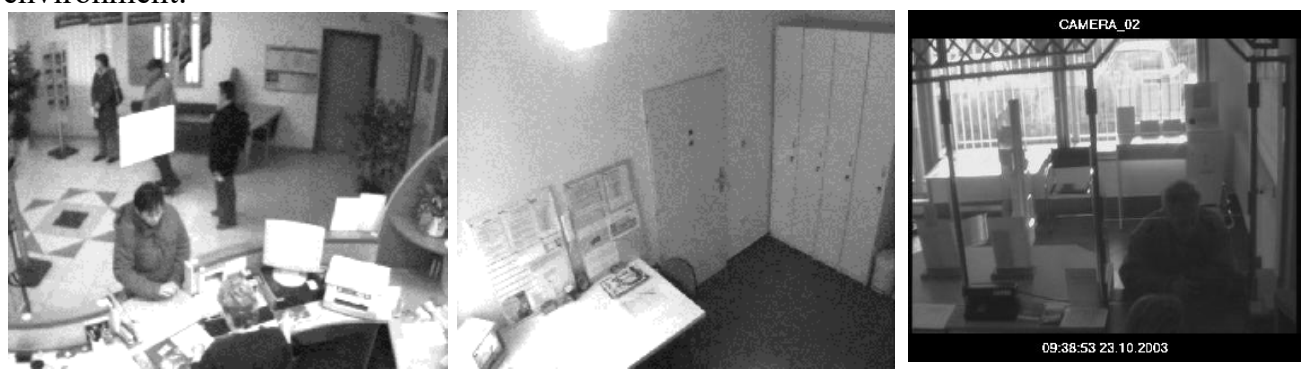

Fig. 1. Black and white photos from security and monitoring systems. Source: Author (2018).

Figure 2 shows an enhanced security system with colour resolution and higher sharpness and details.
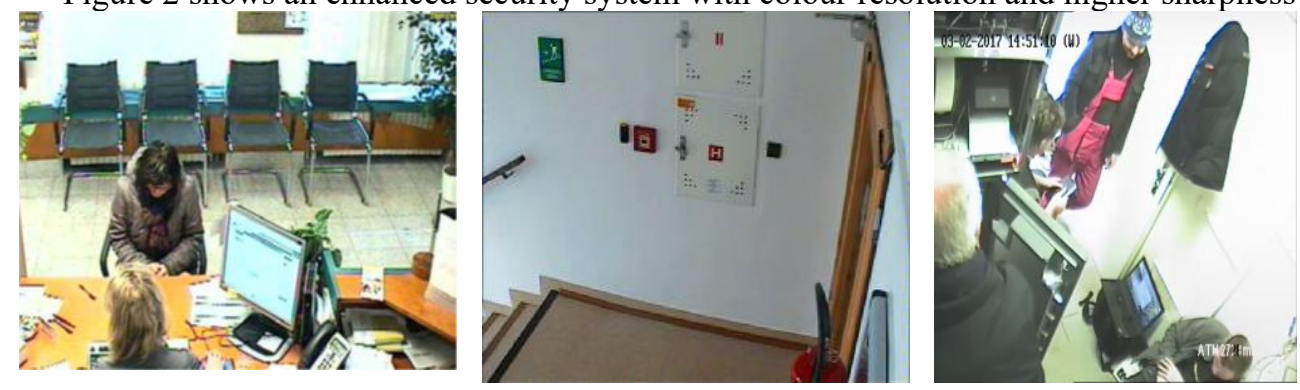

Fig. 2. Colour photos from security and monitoring systems. Source: Author (2019). 
The lowest prices were negotiated for the individual activities of security and monitoring systems as a result of economy measures and a price list of technologies and works was created and is updated every six months to reflect the market price development. In terms of the quantity of products, quantity discounts were negotiated with selected producers and the reduction of material prices (DVR recorder of recording cameras and equipment, IP cameras, etc.) was supported by the trend of the modern technological era in the digital society of the 21 st century as well as affordable prices of the electronic security system and equipment producers. According to the approved plan, secured ATMs (automated teller machine) were switched from the reach of the Police of the Czech Republic to the agency branch with a monitoring control centre. Furthermore, the number of contractors and subcontractors was reduced to reflect the parameters of the catchment area and technological capabilities of deliveries.

The contractors could not be checked for services and activities associated with security (physical protection), assistance services and rapid deployment forces because of the permanent lack of qualified IT workers in the labour market. The decision on the scope of partial reconstruction in order to produce a detailed feasibility case study based on a budget and work schedule has fostered a more transparent investment process intended for the involved parties and co-operating departments of the bank who started to co-operate more closely and communicate more regularly, including compliance with task deadlines and reporting of the project outcomes.

The necessary data and information was defined for building passports that can be used for monitoring, classification, billing, reporting and controlling of the cost centre in the administrative building in the format of numerical series transported to the information system; translated, standard or reduced tax codes, building characteristics, e.g. categorisation of the branch, headquarters and archives and ATM (automated teller machine), translation of the address by the current point of contact, including house numbers as well as categorisation by importance and number of permanent employees.

In 2018, the new information systems CAFM and PPS were successfully implemented and installed with the needed functionalities of security, monitoring, protection, and facility management of the bank. The systems also include a module of repair, maintenance, service and inspection requirements, including records (amendments to attachments) in the approval workflow and generating monthly purchase orders for services based on billing of works.

What was the result of installing CCTV systems in and outside the bank? Is a well-installed security and monitoring system able to protect, mislead or prevent hacker attacks? Is it valid to assume that the extension of security camera and monitoring systems helped to reduce crime, which is endorsed by the public statistics of the Police of the Czech Republic demonstrating a clearly decreasing trend of robbery and burglary in the banking institutions. The evidence is based on facts of robbery and burglary in banks, 126 cases and 99 resolved events in 2008 versus 15 cases and 13 resolved events in 2018. In addition, the number of offences has evincible decreased and the identification of offenders and the occurrence of loss or damage and the security and protection of property and buildings have increased. Images from security and monitoring systems helped to identify and catch persons and criminals since the integrated security project has improved the quality and process of security and protection of property and persons, including a timeless security effect.

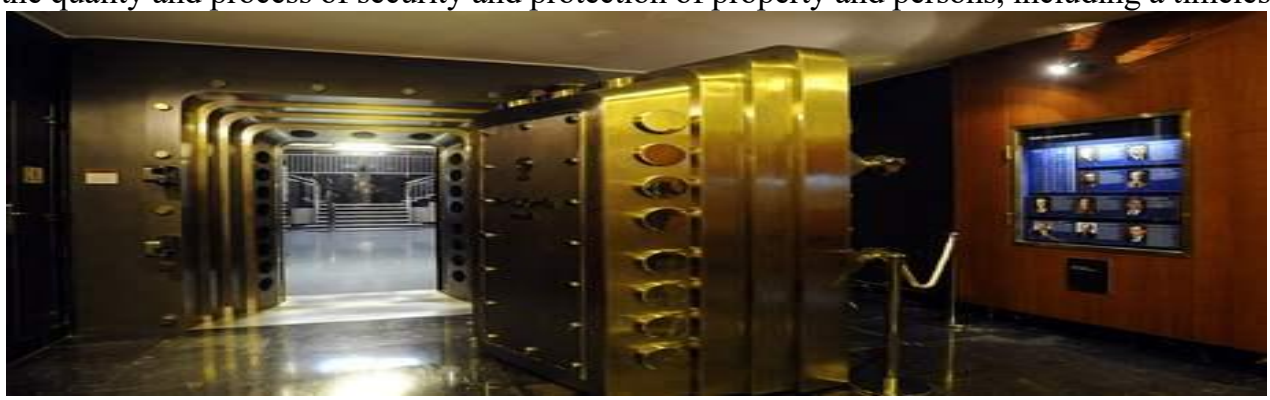

Fig. 3. Colour images from security and monitoring systems for identification of persons and criminals. Source: Author (2019).

\section{Discussion}

\subsection{Project impacts and current state of security and protection in banking institution}

The reasons for the termination of the project were changes in the contractual agreements related to market prices, conditions of part-deliveries, changes in the organizational structure including personnel changes, as well as access functionalities in terms of security, property and persons protection except for customers/clients and suppliers as project partners.

In the integrated security project, there was a stagnation with a gradual decline, to which the supplier (integrator) failed to react, did not maintain the volume of the supplies in the original structure and the stated volume of orders. In the event of any change, the suppler was expected to notify the banking institution and suggest modifications, changes, and innovations during the project implementation phase in order to prevent, protect, eliminate theft, fraud or potential losses or other sophisticated hacker attack. Unfortunately, this did not happen. Client security modified by the new organizational structure allocated the limited powers of the Property Management Department, the organizational structure of the branch was streamlined in favour of the newly created position of the Security Manager, at the expense of the position of the Security Department Director. 
The branch network optimization process consisted in reallocating and reducing the number of branches in order to reduce the number of activities in the field of security and property and persons protection. During several years, the branches from the less frequently visited places were relocated to more attractive, better accessible places, e.g. in shopping centres and squares with a higher number of local inhabitants of the CR, since these multipurpose premises are guarded by security services with a higher number of employees in security and repression services. In cooperation with the Police of the Czech Republic, problem and risky localities were identified, where the branches were not located. The reason was the protection of people, including monitoring, premises protection, and prevention of harmful events. The number of branches was gradually reduced from 650 to 510 , with a total number of 1350 ATMs. Within the optimization of the branch network, a new system called Cashless was installed, which reacts to the current trends in the field of cyber security to reduce the volume of cash payments and transactions with a reduced number of clients/customers visiting the branch networks for cash deposit / withdrawal.

Table 2. Advance in security camera systems.

\begin{tabular}{|c|c|c|}
\hline Marking/Format & PAL/NTSC & Pixels \\
\hline $4 \mathrm{~K} / 2160 \mathrm{P} / \mathrm{UHD} / \mathrm{QFHD}-$ aspect ratio 16:9 & $4096 \times 2160$ & $8847360 / 9 \mathrm{MPx}$ \\
\hline 5M - aspect ratio 4:3 & $2592 \times 1944$ & $5038848 / 5 \mathrm{MPx}$ \\
\hline $4 \mathrm{M}$ - aspect ratio 16:9 & $2688 \times 1520$ & $4085760 / 4 \mathrm{MPx}$ \\
\hline 3M - aspect ratio 4:3 & $2048 \times 1536$ & $3145728 / 3 \mathrm{MPx}$ \\
\hline $2 \mathrm{M} / 1080 \mathrm{P} /$ Full HD - aspect ratio 16:9 & $1920 \times 1080$ & $2073600 / 2 \mathrm{MPx}$ \\
\hline $1,3 \mathrm{M} / 960 \mathrm{P} / \mathrm{HD}$ - aspect ratio 4:3 & $1280 \times 960$ & $1228800 / 1.3 \mathrm{MPx}$ \\
\hline $1 \mathrm{M} / 720 \mathrm{P} / \mathrm{HD}$ - aspect ratio 16:9 & $1280 \times 720$ & $921600 / 1 \mathrm{MPx}$ \\
\hline
\end{tabular}

Source: Author (2019).

FULL HD (1920 x 1080x), widely used in the $21^{\text {st }}$ century digital society, records sharp images in a demanding environment of camera systems, as seen in Table 1 (Advance in security camera systems). Technological advance and development of digital cyber society increased the number of images per second from 100 to 120, with a minimum light exposure / light sensitivity of 0.02 lux. The new product series, especially of panoramic cameras, offer high-quality HD and images with a maximum resolution of 8160 x 3616, 32MP with 30 FPS image resolution for smooth video preview and playback.

\section{Conclusion}

As it was mentioned in the introduction of the paper, the author focused mainly on the description of the integrated security, property, and person's protection project, recapitulation of the results, and the interpretation of the project impacts. On the basis of the current state and existing possibilities of making adaptations and project changes, the author proposes innovations of electronic, information, and data systems and transfers used progressively in the banking environment without higher financial participation in order to improve and increase efficiency, operability and progressive trends. The individual system modules allow to enter more detailed and structured data, improve the data export into the software system, to create operational, accounting, control, and management statements. The project outputs are linked to an active and responsible approach and the behaviour of the banking institution management and employee behaviour.

After gradual replacement of all analogy cameras with digital ones it was possible to evaluate the benefits and shortcomings of new security camera systems by means of camera functions and additional software for security and protection, business and marketing activities, as well as conceptual management.

Analysing the initial and current situation including the results achieved and partial project activities it can be stated that in terms of the original assignment, the integrated security and property and persons protection project, the project objectives were achieved thanks to interested persons and business partners. The persons involved in the project included ordinary security workers, administrative workers, technology installers, heads of individual departments, external consultants and lawyers, who during the ten years of the bank institution existence contributed to achieve the project goals in accordance with the appeal of higher security and property and persons protection. Although future measurable objectives had not been formulated in advance (e.g. the number of cameras installed, maximum extent of damage, number of attack to buildings or ATMS), there has been a positive change in the last decade of the 21 st century digital society consisting in a radical reduction of number of attacks, thefts, and robberies in banking houses, as evidenced by public police statistics [17]. The installation of more modern and high-quality technologies, as well as the overall increase in the number of security and camera systems contributed to reducing the number of attacked banking houses and to solve the attacks, thefts, and robberies. This primary benefit had a slightly negative secondary effect on the security and property and persons protection in the form of reducing the number of jobs in property and object protection, security specialists, and supplier quality specialists.

Another important finding was that with the reduction in the number of attacks, thefts, and robberies, the importance of security department decreased on the side of a client/customer. On the basis of this situation, it can be stated that the field of security and property and persons protection did not mean any added value generating prosperity 
and economic profit, but the social benefit of responsible behaviour and prevention within the proposed measures preventing risk and milestones at the expense of entry costs of services, technical adjustments, technological innovations and other operational and financial activities. The reduction in the security and protection personnel including the reduction of the budget for project items is the logical result of the existing problem-free situation.

The author of the paper sees that the previously set general goals, such as optimization of the person security and property protection, simplification of the processes, and the improvement of the communication with the subjects appears to be a non-specific strategic vision of the banking institution. The impact and the extent of the competence in terms of person security and property protection has not been analyzed, although the current trend of reducing costs prefers this tendency. In addition, the concept and action plan of the original and the follow-up project in the extent of reorganization changes and other measures was missing. The management of the banking institution was presented with a proposal to optimize person security and property protection, as well as their stabilization in the medium term for the period of $3-5$ years. Surprisingly unplanned but more beneficial and evolutionary overlap of the project consisted in the passportiszation and categorization of objects and the allocation of the input costs. The plan for implementing operational portals by requirements, related annexes, and written documentation was achieved. Web interface, software applications, and data transfers with the necessary functionalities replace the previous inconsistent forms of ordering services and support activities. The added value of the information systems and operational portals were permanent storage of the input data that have the function of setting the parameters, reporting and statements, export transfer activities and streamlining of services provided and partial supporting activities. The passportisation was complemented by a new costs statement and automatic statistical orders that were executed in accordance with the original plan and in comparison with sophisticated IT platforms. The use of system tools was timeless and beneficial in terms of security and persons and property protection with high added value and explanatory power. The synergy effect of newly installed information and communication technologies was the reduction of services, modification, service and revision of technologies, more user-friendly control of remote management and IP technologies, including individual technical tasks and operational activities.

The volume of related supplies, services provided, and revenues from sales decreased, because the planned extension of the branch network was stopped and conceptually modified. Innovative technologies have replaced the workforce, mainly the physical protection of property, installed web portals, electronic and information systems have replaced email or telephonic orders and time-consuming administration of written documents, e.g. in the case of received and sent invoices and orders, which were replaced by electronic invoices with electronic signature.

Retrofitting was in accordance in the technological advance and development in the area of security and person and property protection. A significant benefit is a gradual replacement of black and white cameras with colour IP cameras with higher image resolution and MPx space size and wide shot with possible zooming. The images from previously installed CCTV systems had lower resolution; the photographic documentation was taken in black and white with inaccurately specified subjects and poor backlight.

New quality CCTV systems operate in colour resolution with the advantage of high sharpness, transmission, and detail. The trend of modern technology in the 21 st century digital society is to reduce the costs of the DVR and IP cameras. In the near future (in this or next century), the expert and user community expects new use of CCTV systems with higher resolution. IP camera and software enable to identify persons by their age and sex, recognition of objects and the faces of clients/customers and business partners, identify persons by their number, and other innovative and sophisticated supporting activities. The camera software function enables to programme luggage left in a monitored area, watch the facial expression and movement of persons in the shared areas of user premises and common areas. It is also able to recognize unusual gestures, facial expression and behaviour of individual persons and target groups. New camera functions and additional software is suitable for practical use in the area of security and property and person protection, e.g. in the case of identification of an offender or elimination of risk and damage occurrence.

The interaction between the behaviour of a customer/client, facial expression [18], physical activity, and other factors has a significant impact on the functionality and efficiency of the service system and customer service in terms of obtained input data and information about persons, waiting and check-in time according to the parameters set. A general trend of a circular economy is the reduction of cash transactions in the Czech financial market by reducing the number of payment points and terminals, which influences the number of bank branches and their replacing with cashless banking operations. Through this change it is possible to appeal to the prevention of security risk and milestones, since cash receipt / dispensation is not possible at banking institutions branches. Preventing the transfer of banking operations also prevents the risk of theft, robbery or property damage.

The obtained data and information on camera security and monitoring systems supported by technological advance and the development of the 21 st century digital society brings a synergy effect in integrated security and property and person protection, as well as better use of marketing and communication tools for customers/clients in the area of product policy innovation and extended services provided. Multipurpose use and benefits are indisputable, expected future is an operative fact, not only a topic for medium term. There is a big question mark over the further development in the area of security, person and property protection, and a lot of unspoken questions in terms of legal, ethical, moral, social, economic, environmental and business issues, with an accent on maximizing the use of technological opportunities, marketing and communication tools of business policy and strategy in accordance with Industry 4.0. With regard to the current macroeconomic situation in the Czech Republic and the prediction of GDP per capita development, unemployment rate, inflation rate, balance of payments, and other economic indicators of the real economy, Czech citizens do not have to be afraid to invest in banking houses, since CCTV systems provide security and 
property and persons protection in both active and passive banking operations, since they significantly contribute to the prevention and protection of property and persons. The installation and configuration of CCTV systems is much easier, faster and potentially more economical than it was in the information, not digital society of the 21 st century.

\section{References}

1. G.J. Hwang, S.M. Yang, A study for the object tracking method between cameras in mass video surveillance environment. Advanced Science Letters, 22(11), 3247-3251 (2016). DOI: 10.1166/asl.2016.7963.

2. L. Lopez-Fuentes, J. van de Weijer, M. González-Hidalgo, H. Skinnemoen, A.D. Bagdanov, Review on computer vision techniques in emergency situations. Multimedia Tools and Applications, 77(13), 17069-17107 (2018).

3. R.D. Putra, A.L. Prasasti, T.W. Purboyo, Analysis of retinex algorithm on digital image from CCTV camera for face recognition. Journal of Theoretical and Applied Information Technology, 96(23), 7942-7962 (2018).

4. S. Cho, E.-M. Yang, C. Seo, Multiple number plates recognition system implementation using HD CCTVs. Far East Journal of Electronics and Communications, 17(3), 643-649 (2017). DOI: 10.17654/EC017030643.

5. A. Vel'As, M. Kutaj, M. Durovec, Influence of changing the parameters of the camera system on video-based motion detection. In Proceedings of 2017 International Carnahan Conference on Security Technology (ICCST) (pp. 1-5). IEEE (2017). DOI: 10.1109/CCST.2017.8167829.

6. W.C. Choi, J.Y. Na, Study on real-time crime response service using multi-CCTV collaboration technology. In ICCBDC'18 Proceedings of the 2018 2nd International Conference on Cloud and Big Data Computing (pp. 78-81). ACM International Conference Proceeding Series. New York, N.Y.: ACM (2018). DOI: 10.1145/3264560.3264573.

7. V.M.E. Jacintha, S. Jamuna Rani, J. Glory Beula, J. Jeba Johnsly, An extensive resolution of ATM security systems. In: 2017 Third International Conference on Science Technology Engineering \& Management (ICONSTEM), Chennai, India (pp. 934-938). IEEE (2018). DOI: 10.1109/ICONSTEM.2017.8261340.

8. S. Byon, E. Kwon, E.S. Jung, Y.T. Lee, A study on location information aided re-identification in CCTV environment. In Proceedings of 2017 International Conference on Information and Communication Technology Convergence (ICTC) (pp. 817-819). IEEE (2017). DOI: 10.1109/ICTC.2017.8190790.

9. M. Courtney, Stop, thief! Engineering and Technology, 10(4), 70-73 (2015). DOI: 10.1049/et.2015.0440.

10. S. Shammi, S. Islam, H.A. Rahman, H.U. Zaman, An automated way of vehicle theft detection in parking facilities by identifying moving vehicles in CCTV video stream. In Proceedings of 2018 International Conference on Communication, Computing and Internet of Things (IC3IoT) (pp. 36-41). IEEE (2018). DOI: 10.1109/IC3IoT.2018.8668135.

11. L.M. Dang, S.I. Hassan, S. Im, I. Mehmood, H. Moon, Utilizing text recognition for the defects extraction in sewers CCTV inspection videos. Computers in Industry, 99, 96-109 (2018). DOI: 10.1016/j.compind.2018.03.020.

12. Y.H. Kim, G.W. Bang, Development of security camera combined beacon signal for transmission of disaster and crime situation as well as tracking location. International Journal of Engineering and Technology, 7(2), 141-144 (2018).

13. H. Gupta, P. Chaudhary, An efficient face parts detection technique for CCTV surveillance. In 2017 International Conference on Innovations in Control, Communication and Information Systems (ICICCI) (pp. 1-6). IEEE (2019). DOI: 10.1109/ICICCIS.2017.8660814.

14. A.A. Adams, J.M. Ferryman, The future of video analytics for surveillance and its ethical implications. Security Journal, 28(3), 272-289 (2015)

15. A.I. Adrian, P. Ismet, P. Petru, An overview of intelligent surveillance systems development. In Proceedings of 2018 International Symposium on Electronics and Telecommunications (ISETC) (pp. 1-6). IEEE (2018). DOI: 10.1109/ISETC.2018.8584003.

16. H. Al-Kawaz, N. Clarke, S.M. Furnell, F. Li, A. Alruban, Advanced facial recognition for digital forensics. In A. Jøsang (Ed.), Proceedings of the 17th European Conference on Information Warfare and Security. ECCWS 2018 (pp. 11-19). Academic Conferences and Publishing International Limited. (2018).

17. J. Wickes, Facial recognition: Designing 21st century rules. Biometric Technology Today, 10, 7-10 (2018). DOI: 10.1016/S0969-4765(18)30157-7.

18. W. Yimyam, T. Pinthong, N. Chumuang, M. Ketcham, Face Detection Criminals through CCTV Cameras. In Proceedings of the 14th International Conference on Signal-Image Technology \& Internet-Based Systems 2018 (SITIS) (pp. 351-357). IEEE (2019). DOI: 10.1109/SITIS.2018.00061. 